\title{
PRODUÇÃO TEXTUAL EM CONTEXTO DE ENSINO SUPERIOR: REDISCUTINDO PERSPECTIVAS E PROCEDIMENTOS DE ENSINO-APRENDIZAGEM
}

\author{
Petrilson PINHEIRO*
}

- RESUMO: O artigo tem como objetivo apresentar e discutir resultados de uma investigação de base qualitativo-interpretativista dos procedimentos de ensino-aprendizagem utilizados em uma disciplina voltada exclusivamente para leitura e produção de textos acadêmicos do Programa de Formação Interdisciplinar Superior (Profis) da Universidade Estadual de Campinas (Unicamp), no período de 2013 a 2016. Como aporte teórico, este estudo toma como base a perspectiva sociocultural de Vygotsky $(2000,2003)$ e, particularmente, seu conceito de Zona de Desenvolvimento Proximal (ZDP), aliado aos conceitos de Mastery Learning (BLOOM, 1971), feedback recursivo (COPE; KALANTZIS, 2016) e Scaffolding (BRUNER; ROSS; WOOD, 1976). Os resultados mostram que se a produção textual for trabalhada por meio de um processo de avaliação formativa, de caráter prospectivo e construtivo, fornecendo um contínuo feedback para os aprendizes, é possível levá-los a novas formas de conhecimento, em que os andaimes necessários, construídos tanto com a ajuda de pessoas mais experientes, quanto por meio de seus próprios pares, podem, então, transformar seu desenvolvimento potencial, que se relaciona às capacidades e conquistas a serem obtidas pelos discentes, em desenvolvimento real, concernente às àquelas que já foram por eles atingidas.

- PALAVRAS-CHAVE: Produção textual. Ensino superior. ZDP. Scaffolding. Mastery learning. Feedback recursivo.

\section{Introdução}

A partir do século XIX, se consolidou, de fato, uma cultura grafocêntrica, em que se constituiu a necessidade de tornar universal o acesso ao saber, transformando a (aprendizagem da) escrita em um elemento de hierarquização social (CERTEAU, 1984). A aquisição da escrita passou a se tornar elemento imprescindível não apenas para exercer diversas profissões, mas também para a própria inserção social e política, isto é, tornou-se pré-condição para que os indivíduos pudessem ser definidos, em última análise, como cidadãos em muitas sociedades.

\footnotetext{
Universidade Estadual de Campinas (UNICAMP), Departamento de Linguística Aplicada, Campinas, São Paulo, Brasil.petrilson@iel.unicamp.br. ORCID: 0000-0002-4066-9636.
} 
Se no contexto da vida social mais ampla, a escrita passou a ter uma importância cada vez maior e mais generalizada, é nas instituições de ensino superior que assume condição sine qua non, tanto para os que nelas querem entrar, quanto para os que nelas querem se manter ${ }^{1}$. No entanto, esse poder da escrita, que deveria ser usado como força agregadora de inclusão social, desempenha, justamente, o papel contrário de hierarquizar e privilegiar, a partir da perspectiva da meritocracia, o aprendizado individualista da escrita, que, por sua vez, se torna um produto cada vez mais valioso, que determina o sucesso e o fracasso, o prestígio e a discriminação social do próprio discente. Nesse sentido, basta notar o quanto as universidades, sobretudo as públicas, ainda são loci de exclusão social e cultural.

Pensando, portanto, em olhar para a escrita, mais particularmente para a produção textual, como possibilidade de inclusão discente no ensino superior, este artigo tem como objetivo realizar, como base na perspectiva sociocultural de Vygotsky (2000, 2003) e, particularmente, em seu conceito de Zona de Desenvolvimento Proximal (ZDP), aliado aos conceitos de Mastery Learning (BLOOM, 1971), feedback recursivo (COPE; KALANTZIS, 2016) e Scaffolding (BRUNER; ROSS; WOOD, 1976), uma análise e discussão dos procedimentos de ensino-aprendizagem utilizados em uma disciplina voltada exclusivamente para leitura e produção de textos acadêmicos do Programa de Formação Interdisciplinar Superior (Profis) da Universidade Estadual de Campinas (UNICAMP), no período de 2013 a 2016.

\section{A perspectiva sociocultural de aprendizagem vygotskyniana}

A perspectiva sociocultural de Vygotsky parte do princípio de que a aprendizagem humana não acontece por processos diretos com o meio, mas por mediações entre os sujeitos e o meio em que vivem, já que o funcionamento psicológico se fundamenta nas relações sociais entre indivíduos e o mundo exterior, que se desenvolvem dentro de um contexto sócio-histórico (VYGOTSKY, 2003). Para Vygotsky, é a partir das relações interpessoais e com o mundo social que ocorre o desenvolvimento intrapessoal, que se refere à capacidade de pensar sobre si mesmo, sobre a realidade e de agir sobre ela (VYGOTSKY, 2003). A esse respeito, Wells (1999) aponta que os sujeitos se apropriam dos conhecimentos disponíveis do mundo a partir das relações com os outros. Isso, então, permite considerar que o sujeito é ativo em seu desenvolvimento. Nesse sentido, características internalizadas, que se tornam individuais, como: modo de agir, de pensar, de sentir, valores, conhecimentos, visão de mundo etc., são, portanto, frutos da interação do sujeito com o ambiente social no qual está inserido.

Vale, contudo, enfatizar que o fato de Vygotsky atribuir ao meio social o papel de propulsor da aprendizagem e, consequentemente, do desenvolvimento nos processos

Nota-se o quanto o Enem e diversos vestibulares valorizam a prova de redação nos processos seletivos para entrada nas as universidades públicas brasileiras. 
históricos e culturais não implica um determinismo social que enxerga o indivíduo como uma espécie de fantoche à mercê da história e da cultura. Vygotsky, ao contrário, entende essa relação sujeito e mundo social a partir de um processo sempre dialético, pois, se por um lado, o indivíduo é moldado pelas relações sociais decorrentes das interações em contextos históricos e culturais diversos, ele também molda e transforma essas relações, contribuindo, desta forma, para um processo em constante transformação.

Para Vygotsky, o conhecimento não é compreendido como um produto direto do sujeito sobre a realidade, mas, por meio de diversas relações entre os sujeitos, os objetos e o meio em que vivem. Assim, pode-se dizer que, em todo processo de construção e apropriação de conhecimento, é necessária a mediação, que, nada mais é que a intervenção de alguém para que um outro se aproprie da cultura constituída sócio-historicamente, o que é viabilizado, principalmente, por meio da aprendizagem.

Nessa perspectiva, Vygotsky entende também que o processo de mediação sofre transformações ao longo do desenvolvimento do sujeito, pois a experiência com o mundo objetivo e o contato com as formas construídas socioculturalmente possibilitam o sujeito construir seu próprio sistema de signos, por meio do qual compreende o mundo à sua volta (BLANK, 1996). Nesse sentido, a linguagem passa a ter, para Vygotsky, uma profunda importância, uma vez que se trata de um sistema simbólico fundamental que organiza os signos em estruturas cada vez mais complexas, possibilitando que os sujeitos desenvolvam sua capacidade humana de interação social, reflexão, prática, socialização, transformação social.

É possível, assim, afirmar que, se na perspectiva vygotskyniana, o processo de aprendizagem se constitui por meio da interação entre pessoas e instrumentos socioculturais, então, é a partir do processo de interação com os outros, ou mais especificamente com pessoa(s) mais experiente(s) e com o contexto histórico-cultural, que os sujeitos podem desenvolver suas potencialidades. Isso, por sua vez, se remete a um conceito basilar vygotskyniano no processo de aprendizagem: o de "Zona Desenvolvimento Proximal" (ZDP).

Para Vygotsky, a aprendizagem ideal deve ser aquela que promove o desenvolvimento: o ensino não implanta novas funções psíquicas no sujeito, mas cria condições para que ele as possa construir (VYGOTSKY, 2003). Desse modo, pode-se dizer que as potencialidades do sujeito devem ser consideradas durante o processo de ensinoaprendizagem. Essas potencialidades podem ser transformadas a partir do contato com uma pessoa mais experiente e com o contexto histórico-cultural, produzindose, assim, nesse sujeito, novas potencialidades, num processo dialético contínuo de criação e recriação de conhecimentos, conceitos, crenças e valores do mundo em que vive. Segundo o autor, esse processo dialético se constitui a partir de dois níveis de desenvolvimento: o desenvolvimento real, ou seja, aquele que se refere às conquistas já atingidas pelo indivíduo (corresponde àquilo que o sujeito já é capaz de realizar sozinho); e o desenvolvimento potencial, definido como aquele que se relaciona às capacidades e conquistas a serem construídas (é o desenvolvimento relacionado com a capacidade de fazer algo, mas que depende da ajuda de (um) sujeito(s) mais experiente(s)). 
Nesse sentido, a concepção de que o processo de aprendizagem se constitui por meio da capacidade do sujeito de resolver problemas e realizar ações que estão além do seu nível de desenvolvimento com o auxílio de um par mais competente desencadeou a elaboração do conceito de ZDP. Segundo Vygotsky (2003, p.112), a ZDP se caracteriza como a "[...] distância entre o nível de desenvolvimento real, que se costuma determinar através da solução independente de problemas, e o nível de desenvolvimento potencial, determinado através da solução de problemas sob a orientação de um adulto ou em colaboração com companheiros mais capazes." Assim, o conceito de ZDP pressupõe que as relações interpessoais se tornam elementos centrais nos processos de desenvolvimento e aprendizagem, uma vez que o par mais competente identifica e atua na ZDP do aprendiz, para que este venha a atingir um nível mais elevado de reflexão sobre a atividade em jogo.

Vygotsky ainda nos chama a atenção para o fato de que "[...] o desenvolvimento se dá não em círculo, mas em espiral, passando por um mesmo ponto a cada nova revolução, enquanto avança para um nível superior [...]" (VYGOTSKY, 2003, p. 74). Isso quer dizer que a ZDP não deve ser encarada dentro de uma visão simplista e mecânica como a pura transferência de habilidades e conhecimentos daqueles que sabem mais para aqueles que sabem menos, mas deve ser vista dentro desse movimento em espiral, no qual as relações entre aprendizagem e desenvolvimento, emergentes das interações decorrentes das mais diversas esferas do meio social, são extremamente complexas, não podendo, portanto, ser reduzidas a uma forma única e imutável.

Embora o conceito de ZDP traga uma contribuição conceitual basilar para entender a construção de conhecimento no processo de ensino-aprendizagem, notase, contudo, que a teoria não apresenta elementos que possam, de fato, torná-la operacionalizável, isto é, faltam dispositivos teórico-analíticos que a tornem aplicável em práticas de ensino-aprendizagem. Na tentativa, então, de operacionalizar a perspectiva vygotskyniana e o seu conceito de ZDP, busca-se, neste artigo, aliá-lo aos conceitos de Mastery Learning (BLOOM, 1971), feedback recursivo (COPE; KALANTZIS, 2016) e Scaffolding (BRUNER; ROSS; WOOD, 1976).

\section{Mastery learning, feedback recursivo e Scaffolding: conceitos em diálogo com a perspectiva sociocultural vygotskyniana}

Pode parecer estranho tentar juntar neste artigo duas perspectivas que, em princípio, são divergentes: a perspectiva sociocultural vygotskyniana e a perspectiva do Mastery Learning, de Benjamin Bloom, de caráter behaviorista. Com efeito, se se observá-las exclusivamente em sua essência conceitual, tais perspectivas podem, em princípio, não dialogar entre si. Isso porque, enquanto a perspectiva do Mastery Learning busca desenvolver meios e técnicas que possibilitem controlar e prever comportamentos e resultados que sejam mensuráveis e observáveis, a perspectiva vygotkyana, ao 
contrário, se constitui como algo mais dialógico, fluido e, por isso, menos controlável e previsível, no que diz respeito a comportamentos e resultados relativos ao processo de ensino-aprendizagem.

Contudo, um ponto fulcral comum às duas perspectivas, ainda que tratado com focos um tanto distintos, é a centralidade de fatores de ordem contextual, em que o sujeito-aprendiz é visto em sua individualidade. Com base, então, nessa característica fundante, busca-se neste artigo mostrar que é possível pensar em metas de ensino presumidamente claras e objetivas - o que é característico da perspectiva do Mastery Learning - como forma de atuar na ZDP dos aprendizes, buscando, assim, usar alguns conceitos concernentes a essas perspectivas como dispositivos teórico-analíticos em um contexto de ensino-aprendizagem de escrita.

O conceito de Mastery Learning, desenvolvido nos anos de 1960 por Benjamin Bloom, partia do pressuposto geral que, em condições de ensino-aprendizagem apropriadas, a grande maioria dos alunos seria capaz de aprender. Para Bloom (1971, p. 49, tradução do autor), uma “[...] tarefa fundamental em educação é desenvolver estratégias que tenham em conta as diferenças individuais por forma a promover, em vez de inibir, o desenvolvimento individual pleno."

Ainda segundo o autor, o fato de os professores buscarem ensinar todos os alunos do mesmo modo, a que se referia como "instrução uniforme clássica", e de atribuírem o mesmo tempo para todos os alunos aprenderem era o que justamente originava as disparidades nos seus desempenhos. Assim, o grande objetivo de Bloom era, então, encontrar um modelo instrucional ${ }^{2}$ que permitisse anular ou, pelo menos, reduzir essas disparidades entre os alunos. Para conseguir fazer com que o desempenho final bemsucedido dos aprendizes seja maior do que aquilo que demostram inicialmente em suas atividades escolares, Bloom (1971) destaca que é necessário, antes de tudo, reconhecer que os estudantes são diferentes entre si, o que implica dizer que a atenção e o método utilizado pelo professor, bem como o tempo para a realização de tarefas, precisam, do mesmo modo, ser distintos. Em outras palavras, para o autor, o tempo de aprendizagem e as condições de ensino são variáveis que determinam o sucesso acadêmico dos alunos.

Bloom e sua equipe de pesquisadores já haviam constatado na década de 1950 que, em condições idênticas de ensino, em que se desconsideram variáveis externas ao ambiente educacional, todos aprenderiam, diferenciando-se, porém, em relação ao nível de profundidade de conhecimento (BLOOM; HASTIN; MADAUS, 1971). Para os autores, a diferença de aprendizagem poderia ser caracterizada pelas estratégias utilizadas e pelo modo de organização dos processos de aprendizagem para estimular o desenvolvimento cognitivo ${ }^{3}$.

2 A ideia de um "modelo instrucional", em princípio, não dialoga com a perspectiva sociocultural vygotskyniana. No entanto, como foi dito acima, interessa a este estudo menos o arcabouço conceitual do modelo Mastery Learning, que é aqui trazido apenas para fazer referência ao texto original de Bloom. O que é mais explorado são os elementos constitutivos do modelo, que podem ser repensados à luz de uma perspectiva sociocultural de aprendizagem.

3 Foi pensando justamente nos processos de aprendizagem para estimular o desenvolvimento cognitivo que Bloom, junto com especialistas de várias universidades dos EUA, ainda na década de 1950, desenvolveu uma taxonomia dos objetivos educacionais, uma espécie de categorização dos domínios cognitivos, em uma estrutura de organização 
Com base, então, na concepção de que, em condições de ensino-aprendizagem apropriadas, os aprendizes seriam capazes de aprender, embora com níveis de profundidade de aprendizagem distintos entre si, Bloom (1971) desenvolve a sua proposta de Mastery Learning, que se constitui por meio de três elementos fundamentais: o feedback, atividades de remediação ${ }^{4}$ e enriquecimento e avaliação formativa. Em linhas gerais, o feedback é a atividade consecutiva à tarefa que o aluno deve realizar, passando para a tarefa seguinte da qual recebe novamente feedback e assim sucessivamente. À medida que se avança nas tarefas, estas se tornam progressivamente mais complexas; todavia, com ofeedback continuo e individualizado, que respeita os tempos e capacidades dos discentes, estes se sentiriam motivados a continuar se desenvolvendo. Segundo Bloom (1971), por meio de feedback, o professor pode apontar certas fragilidades e caminhos de resolução de questões dos discentes de forma contínua, acompanhando-os constantemente e conseguindo, assim, a melhoria dos seus resultados.

Entretanto, o feedback se torna ainda mais eficaz, de acordo com o autor, se estiver articulado com atividades de remediação e enriquecimento, que se constituem como atividades práticas (tutorias ou trabalho em grupo, exercícios mais complexos, e/ou pesquisas na internet, por exemplo), cujo objetivo é proporcionar aos estudantes experiências de aprendizagem que lhes permitam aprofundar suas potencialidades e explorar conteúdos aprendidos, que se adaptariam, assim, às suas singularidades.

O Feedback e as atividades de remediação e enriquecimento, por sua vez, seriam mais eficientes se estiverem atreladas à avaliação formativa. Nesse sentido, ao enfatizar a importância da avaliação formativa como forma de reduzir as discrepâncias entre os resultados dos estudantes, Bloom (1971, p. 7, tradução do autor) assevera que “[...] testes frequentes de avaliação formativa estimulam o aprendizado dos alunos e ajudam a motivá-los a realizar o esforço necessário no momento apropriado."

Assim, a avaliação formativa não tem propriamente a função de "medir" o que os estudantes já sabem e lhes atribuir uma nota. Sua função, inicialmente, é possibilitar que o professor possa detectar as dificuldades de aprendizagem dos discentes e rever as estratégias de ensino. Em seguida, por meio de diversas atividades de remediação, com a ajuda do professor ou através de formas alternativas de aprendizagem, como o uso de internet, por exemplo, poder atuar na aprendizagem do aluno, assumindo, assim, uma dimensão fundamentalmente formativa e reguladora.

A avaliação formativa é, portanto, um tipo de avaliação processual dividido em três partes no modelo Mastery Learning: avaliação pré-instrucional, pós-avaliação e avaliação diagnóstica. A avaliação pré-instrucional é usada para determinar os níveis iniciais dos alunos e para ajudar a projetar o mecanismo instrucional mais adequado.

hierárquica, que se divide nas seguintes categorias cognitivas: avaliação, síntese, análise, aplicação, compreensão e conhecimento.

4 Embora a "remediação" tenda a apresentar uma carga semântica negativa, que se remete a "corrigir algum erro" cometido, o que, em muitos casos no contexto de ensino-aprendizagem não se aplicaria ou se justificaria, o termo "atividades de remediação e enriquecimento" será usado como elemento analítico neste estudo com valor positivo, isto é, como atividades que, combinadas ao feedback e à avaliação formativa, promovem um efeito benéfico no processo de aprendizagem dos discentes. 
A pós-avaliação, por sua vez, é usada principalmente para determinar se um aluno cumpriu os objetivos que lhe foram designados. Também pode ser usado para avaliar a própria instrução e refinar objetivos. O terceiro método de avaliação, o diagnóstico, é uma técnica de avaliação formativa utilizada para medir a eficácia das instruções em curso, ou seja, para aprimorar o processo de instrução.

Um conceito que amplia e aprimora a ideia de avaliação formativa do modelo Mastery Learning é o de feedback recursivo (COPE; KALANTZIS, 2016). Para os autores, diferentemente da dimensão avaliativa da Pedagogia Didática ${ }^{5}$, que adota a avaliação somativa, um modelo de avaliação que tem um caráter de julgamento retrospectivo e pontual, que ocorre ao fim de um processo educacional, o feedback recursivo se constitui através da avaliação formativa, de caráter prospectivo e construtivo, que fornece feedback para os aprendizes e seus professores durante o próprio processo de aprendizagem. Nesse sentido, Cope e Kalantzis (2016, p. 34-35 tradução do autor) sugerem cinco proposições para uma agenda para o futuro da avaliação:

1. A avaliação pode ser cada vez mais incorporada à instrução, permitindo-nos realizar ambições de longa data para oferecer uma avaliação formativa mais rica.

2. Podemos agora ter tantos dados de aprendizagem interina ou de progresso, por que nós ainda precisamos desses artefatos estranhos, como as avaliações somativas? Com a ajuda de dados mashups e visualizações, os pontos de dados precisam ser apenas aqueles localizados dentro do processo de aprendizado. O teste está morto; vida longa à avaliação!

3. Agora que podemos avaliar tudo e não há aprendizado sem feedback reflexivo, recursivo, feedback da máquina, feedback de pares e professores e auto-reflexão estruturada, nós ainda precisamos de uma distinção entre instrução e avaliação? Não deveria haver instrução sem feedback recursivo incorporado e não há feedback que não contribua diretamente e de forma incremental para a aprendizagem. A Pedagogia Reflexiva encerra com a distinção entre avaliação e instrução.

4. O foco do que é avaliável agora muda da cognição individual, para os artefatos da representação do conhecimento e sua proveniência social. Não se trata mais do que você pode lembrar, mas o artefato do conhecimento que você pode criar, reconhecendo suas fontes em memória coletiva através de links e citações, e rastreando o processo de construção colaborativo através dos feedbacks oferecidos por pares e professores, bem como as revisões feitas em resposta.

\footnotetext{
Os autores apontam um quadro comparativo entre o que chamam de Pedagogia Didática, o modelo tradicional de ensino vigente nos últimos 200 anos, que adota a avaliação somativa como método de avaliação, e a Pedagogia Reflexiva, em cuja perspectiva se inscreve o que chamam de feedback recursivo e a avaliação formativa.
} 
5. O foco do que é avaliável se desloca da repetição de fatos e a correta aplicação de teoremas para o que chamamos de performance epistêmica complexa, ou os tipos de pensamento analítico que caracterizam práticas disciplinares - ser um cientista ou escritor, ou aplicar matemática a um problema.

A proposta de feedback recursivo, que se constitui através de um processo contínuo e prospectivo de avaliação (formativa), que não se centra na cognição individual, mas nos artefatos da representação do conhecimento e sua proveniência social (COPE; KALANTZIS, 2016), dialoga com outro conceito: Scaffolding. O conceito é uma metáfora que se refere a uma espécie de assistência ou auxílio - verbal ou não verbal que um membro mais experiente (um par mais competente) de uma cultura pode fornecer a um outro. O termo foi inicialmente cunhado por Bruner, Ross e Wood (1976), que tinham como finalidade explicar os meios através dos quais um adulto poderia ajudar uma criança numa relação de ensino-aprendizagem.

O conceito, ainda segundo os autores, se constitui a partir da construção de habilidades, que se tornam cada vez mais "complexas", através de uma apropriada capacidade para lidar com as exigências novas e mais difíceis de uma determinada tarefa, ou seja, trata-se da capacidade de lidar com o aspecto de novidade e de gradação da dificuldade requerida pela tarefa. Nesse sentido, a intervenção de um professor, por exemplo, pode fazer com que o aprendiz resolva um problema, realize uma tarefa ou atinja um objetivo que está além da sua capacidade, servindo, assim, como um 'andaime' necessário para o aprendiz na construção da sua ZDP.

Na tentativa de estabelecer essa relação de "andaimes" entre o aprendiz e o "tutor", Bruner, Ross e Wood (1976) apresentam seis funções específicas na construção de andaimes:

1) "Recrutamento", função que se caracteriza como a primeira tarefa a ser desempenhada pelo tutor e consiste na obtenção do interesse e na adesão por parte dos aprendizes para que estes se envolvam com as exigências exigidas pela tarefa;

2) "Redução nos graus de liberdade", função que envolve uma espécie de simplificação da tarefa, por meio da redução do número de ações requeridas para alcançar sua solução. A ideia dos autores, nesse caso, é reduzir o tamanho da tarefa para que possa ser reconhecida pelo aprendiz e para que este possa perceber se consegue ou não se "ajustar" às exigências que a tarefa exige. Nesse sentido, o andaime é fornecido pelo tutor a fim de permitir que o aprendiz possa aperfeiçoar a realização da tarefa;

3) "Manutenção da direção", função de manter o aprendiz focado no objetivo proposto, já que ele pode se dispersar do objetivo da tarefa. Nesse caso, a função do tutor é, portanto, a de fazer com que o aprendiz continue a desempenhar a atividade, mas também a de mantê-lo motivado pela tarefa;

6 Como o termo "tutor" (tutor, do inglês) é especificamente usado por Bruner, Ross e Wood (1976) para designar a pessoa que assiste o aprendiz com os andaimes, foi aqui mantido propositalmente nesta parte em que o trabalho dos autores é resenhado. 
4) "Ênfase dos traços críticos", função em que o tutor, através de uma gama de meios, enfatiza determinadas características da tarefa, relevantes para a sua execução, e interpreta as discrepâncias existentes. Essas características possibilitam fornecer informações sobre a discrepância entre o que o aprendiz produziu e o que deveria reconhecer para a realização do trabalho;

5) "Controle da frustração", função que consiste na tentativa de reduzir o stress e a frustração do aprendiz na resolução de algum problema. Isso pode ser obtido com a interferência do tutor para tentar acalmar e trabalhar junto com o aprendiz, sempre que este parecer ansioso na realização de alguma atividade; e

6) "Demonstração", função que busca criar modelos dos procedimentos mais apropriados para atingir os objetivos ou as soluções para as tarefas.

É preciso ainda apontar que, muito embora os autores não façam qualquer referência explícita ao conceito de ZDP, nota-se uma inter-relação entre ambos os conceitos. Wells (1999), a esse respeito, argumenta que o conceito de Scaffolding seria um modo de operacionalizar o conceito vygotskyniano de ZDP, já que este se encontra subjacente àquele. Nesse sentido, o autor (WELLS, 1999, p. 127), então, identifica três características fundamentais do andaime na relação com a ZDP: "1) a natureza essencialmente dialógica do discurso no qual o conhecimento é construído; 2) a significância do tipo de atividade em que o saber é incorporado; 3) o papel dos artefatos que fazem a mediação do conhecimento."

Neste artigo, portanto, mobilizam-se os conceitos de ZDP (VYGOTSKY, 2003), Mastery Learning (BLOOM, 1971), feedback recursivo/ avaliação formativa (COPE; KALANTZIS, 2016) e scaffolding (BRUNER; ROSS; WOOD, 1976), com o intuito de complexificar o processo de desenvolvimento dos aprendizes, tanto na interação com o(s) tutor(es), quanto entre si mesmos. Esses conceitos serão, pois, usados como dispositivos teórico-analíticos em um contexto específico de ensino-aprendizagem: uma disciplina do Profis da Unicamp voltada exclusivamente para leitura e produção de textos acadêmicos.

\section{Contextualização e análise dos procedimentos de ensino-aprendizagem da disciplina de leitura e produção de textos acadêmicos do Profis}

\section{O Profis e a disciplina Leitura e produção de textos acadêmicos}

O Profis é um programa piloto da Unicamp, de caráter interdisciplinar, voltado para estudantes que cursaram o ensino médio em escolas públicas de Campinas, SP. Diferentemente do processo seletivo tradicional do Vestibular Unicamp, o Profis seleciona estudantes (120 vagas no total) por meio das notas do Exame Nacional do Ensino Médio (Enem), garantindo uma vaga para cada escola pública de ensino médio do município de Campinas. 
O Programa tem um currículo que inclui disciplinas de diferentes áreas do conhecimento (humanas, biológicas, exatas e tecnológicas), que são distribuídas por dois anos de curso. Entre as disciplinas ofertadas pelo Profis, há a disciplina LA084 (Leitura e produção de textos acadêmicos II). Essa disciplina, que é pré-requisito da disciplina LA083 (Leitura e Produção de Textos Acadêmicos I), tem como ementa a "leitura e Produção de gêneros prestigiados na esfera acadêmica, em suas diferentes áreas.” (UNICAMP, 2014).

Com base nessa ementa, o professor responsável pela disciplina desenvolveu, a partir de 2013, um programa que visa à leitura, escrita e reescrita de artigos acadêmicos, envolvendo um trabalho com mecanismos de coesão para a construção de textualidade e de articulação sintático-semântica (uso de operadores argumentativos), de estruturação paragrafal (tópicos frasais) e de elementos de concordância e regência nominal e verbal para a elaboração de dois gêneros da esfera acadêmica: resumo e resenha crítica ${ }^{7}$.

Por ter, em média, um número de 100 alunos $^{8}$, a disciplina LA084 é dividida em quatro turmas (A, B, C e D), que incluem tanto aulas teóricas quanto aulas práticas ${ }^{9}$. Para ser, então, possível atender a todas as quatro turmas, o professor responsável contou, a cada ano em que ministrou a disciplina, com dois bolsistas de doutorado e três bolsistas de graduação ${ }^{10}$. Durante o período analisado e avaliado no presente estudo (2013 a 2016), participaram, no total, oito bolsistas de doutorado e doze bolsistas de graduação.

\section{Análise e discussão dos procedimentos de ensino e de avaliação das aulas da disciplina}

Diferentemente do que se poderia esperar de artigos acadêmicos sobre produção textual no ensino superior ${ }^{11}$, cujo foco, em geral, se encontra na análise de textos de estudantes universitários, este artigo se centra em uma análise e discussão dos procedimentos de ensino-aprendizagem utilizados em uma disciplina voltada

\footnotetext{
7 Uma perspectiva de ensino de gênero voltada para o trabalho com gêneros das esferas escolar e acadêmica é a desenvolvida por Joaquim Dolz, Michèle Noverraz e Bernard Schneuwly (2004) em seu texto, cujos procedimentos, do ponto de vista prático, se assemelham com os adotados no presente estudo, embora com um viés teórico distinto.

8 Como a disciplina LA084 tem como pré-requisito a disciplina LA083, os alunos que não são aprovados nesta não são matriculados naquela. Assim, o número de alunos da disciplina pode variar de ano para ano.

9 Todas as aulas práticas são ministradas em quatro salas de informática que contêm 35 computadores cada, todos conectados à internet.

10 Os bolsistas de doutorado e os bolsistas de graduação estavam inscritos em dois programas da Unicamp, respectivamente: o Programa de Estágio Docente (PAD) e o Programa de Apoio à Docência (PED). Sou grato a todos os bolsistas pelo seu apoio: os PEDs: Cláudia Gomes Silva Guimarães, Emiliano Cesar de Almeida, Fernanda Felix Litron, Íria Marjori Schubalski Reisdorfer, Mirielly Ferraça, Rosivaldo Gomes, Roziane Keila Grando e Thalita Cristina Souza Cruz; e os PADs: Alan Victor Pereira de Arruda, Amanda Bastos Souza, Ana Luiza Barretto Bittar, Bruno Cuter Albanese, Gabriel Dainesi, Julia Dias, Lucas Lins Oliveira, Lucas Manca Dal Ava, Marilia Veronese Matheus Felipe Xavier Bueno, Luisa Ianhes Moyses e Rafaela Marques Guimarães Lima.

11 A esse respeito, ver Motta-Roth e Hendges (2010).
} 
exclusivamente para leitura e produção de textos acadêmicos do Profis da Unicamp (a disciplina LA084), no período de 2013 a 2016. Entende-se nesta análise que esses procedimentos se constituem como elementos que mobilizam conceitos fundantes para o processo de ensino-aprendizagem, como os de ZDP (VYGOTSKY, 2003), Mastery Learning (BLOOM, 1971), feedback recursivo/ avaliação formativa (COPE; KALANTZIS, 2016) e scaffolding (BRUNER; ROSS; WOOD, 1976), atuando, com isso, no processo de desenvolvimento dos aprendizes, tanto na interação com os tutores, quanto entre si mesmos.

Deve-se primeiramente destacar nesta análise que os procedimentos adotados se coadunam com as características da disciplina LA084, que tem uma carga semanal total de quatro horas (duas para aulas teóricas e duas para as aulas práticas), distribuídas em quatro turmas (com uma média de 35 alunos por turma). Para, então, atender as quatro turmas era preciso que o professor responsável desenvolvesse todo um trabalho conjunto com os bolsistas envolvidos na disciplina. Como os bolsistas de doutorado são professores ${ }^{12}$, eles poderiam assumir as turmas, ficando, então, responsáveis por conduzir as aulas práticas. Os bolsistas de graduação, por sua vez, apoiavam o professor responsável nas aulas teóricas, os bolsistas de doutorado nas aulas práticas e os alunos da disciplina com as atividades a serem postadas na plataforma de ensino aberto online ${ }^{13}$.

Além das aulas, o professor responsável e os cinco bolsistas se reuniam semanalmente. Nessas reuniões, os bolsistas se envolviam no planejamento das aulas e traziam comentários, dúvidas e dificuldades que os alunos e os próprios bolsistas tinham ao longo do processo, em que todas as decisões relativas ao andamento das aulas eram tomadas em conjunto. Logo na primeira reunião do grupo, foram discutidos e delineados o conteúdo e o método da disciplina. Tomando como base a ementa da disciplina, foi decidido que o foco seria o trabalho com dois gêneros acadêmicos especificamente: o resumo e a resenha crítica. $\mathrm{O}$ objetivo, então, da disciplina era desenvolver um conjunto de procedimentos, conteúdos e atividades que contemplassem, primeiramente, a leitura e produção de resumos, estendendo-se até o final da primeira metade do semestre. Na segunda metade, então, o mesmo seria feito em relação à resenha crítica acadêmica.

O motivo da escolha do resumo se deve ao fato de este ser o gênero acadêmico mais usado no contexto universitário de discentes universitários (MOTA-ROTH; HENDGES, 2010) e, particularmente, dos estudantes da disciplina em questão. Alguns alunos, inclusive, já haviam tido experiência de produção de resumos em outras disciplinas do Profis. A resenha crítica foi, por sua vez, escolhida, por ser tratar de um gênero acadêmico de caráter argumentativo, que, além de expor os elementos referenciais e essenciais de um texto, com a sua descrição minuciosa e sucinta, apresenta o julgamento

12 Segundo as normas que regem o Programa de Estágio Docente, os bolsistas de doutorado podem ministrar aulas em qualquer curso de graduação da Unicamp.

13 A plataforma de ensino aberto online usada foi o TelEduc, disponível para as disciplinas de graduação da Unicamp até 2017. Disponível em: <https://www.ggte.unicamp.br/ea/>. Acesso em: 27 jan. 2017. 
ou a apreciação de quem resenha, manifestando sua avaliação nos seus comentários. Isso envolve elementos de persuasão comunicativa, muitas vezes decisivos, de influência na escolha ou não de um determinado texto para leitura, mostrando sua intenção comunicativa, como também o ponto de vista de quem faz a resenha em relação à obra resenhada.

Nas quatro edições em que foi ofertada (2013 a 2016), a disciplina se iniciava, então, com uma exposição teórica sobre o resumo acadêmico (conceitos, usos, finalidades, destinatários, exemplos). O objetivo da primeira aula era fazer com que os alunos fossem expostos ao contexto de produção do resumo e que percebessem a importância de aprender tal gênero acadêmico. Ao expor os discentes a um gênero já experienciado ou que seria experienciado por muitos deles em contextos reais de ensino-aprendizagem em que atuam, pode-se dizer que isso invoca a função de "Recrutamento" (BRUNER; ROSS; WOOD, 1976), visto que se constitui como uma primeira tarefa docente para obter o interesse e a adesão dos aprendizes, buscando, assim, envolvê-los no decorrer das atividades relativas à aprendizagem do gênero em questão.

$\mathrm{Na}$ aula prática subsequente, os alunos deveriam ler um artigo acadêmico de caráter empírico, seguido pela produção textual de um resumo próprio em relação ao artigo $^{14}$. Todos os textos produzidos pelos discentes foram lidos e avaliados (nota foram atribuídas) pelo grupo (professor responsável e bolsistas). Todavia, vale destacar que, para os discentes, a produção do primeiro resumo não tinha qualquer caráter avaliativo, já que eles não recebiam as notas atribuídas aos seus textos. Nesse sentido, a atividade de produção não se configurou como um teste; a atribuição de notas, seguida por comentários feitos nos próprios textos dos discentes, tinha como objetivo fazer uma avaliação diagnóstica (BLOOM, 1971) sobre os conhecimentos prévios dos aprendizes acerca do resumo acadêmico, o que serviu de ponto de partida para que o grupo pudesse acompanhar e orientar os aprendizes com uma série de atividades para o domínio do gênero.

Nota-se que, do ponto de vista da prática didática, a atividade de produção textual inicial se constituiu como a função Redução nos graus de liberdade (BRUNER; ROSS; WOOD, 1976), cujo objetivo era justamente o de simplificar a tarefa dos aprendizes com base em um único andaime (a exposição teórica da aula anterior). A ideia, nesse caso, era a de que, ao simplificar o tamanho da tarefa, esta pudesse ser reconhecida e executada pelos aprendizes.

Do ponto de vista pedagógico-avaliativo, a proposta de uma produção textual inicial dialoga com a ideia de avaliação formativa na perspectiva do Mastery Learning (BLOOM, 1971), uma vez que se constitui, dentro da avaliação processual, como uma avaliação pré-instrucional, usada para determinar os níveis iniciais dos alunos e para ajudar a projetar o mecanismo instrucional mais adequado. Essa avaliação

14 Todas as atividades de produção textual eram realizadas pelos alunos nos laboratórios de informática, nos quais os discentes tinham acesso a dicionários online, bem como a todo o tipo de pesquisa na internet. A cada edição da disciplina, os textos de base para a produção dos gêneros acadêmicos (artigos, resumos e resenhas) eram reavaliados e modificados. 
pré-instrucional, por sua vez, possibilitou ao grupo, através da mediação, isto é, dos variados meios de que dispunha, traçar caminhos possíveis para atuar nas ZDP dos aprendizes, visto que foi possível, por meio dessa produção inicial, identificar os níveis de desenvolvimento real dos discentes, isto é, o que eles já conheciam e eram capazes de expressar sobre a produção do resumo acadêmico, e o seu desenvolvimento potencial, ou seja, o que eles ainda precisavam aprender sobre esse gênero, com a ajuda do professor, dos bolsistas e dos pares.

Com base na produção inicial, foi, então, pensado um conjunto de procedimentos e atividades para atuação nas ZPD dos discentes, tendo como referências os conteúdos do programa mais geral formulado para a disciplina (ver seção anterior). Para cada conteúdo do programa, foram desenvolvidos três procedimentos basicamente: aula teórica, aula prática e atendimento individual aos discentes. A aula prática trazia um ponto pormenorizado para discussão, com base em exemplos mais gerais, que serviam de parâmetro para os aprendizes tirarem suas dúvidas, tanto em relação à macroestrutura dos gêneros em questão, quanto a aspectos relativos à sua estrutura de composição interna.

As aulas práticas, no entanto, eram os momentos em que era possível notar o desenvolvimento dos discentes. Com efeito, as aulas práticas se constituiriam como oficinas interligadas às aulas teóricas e às reuniões semanais do grupo, por meio de um trabalho sistematicamente planejado, com o objetivo de levar os discentes a produzirem os dois gêneros acadêmicos. Nesse sentido, foram desenvolvidas variadas atividades que envolveram desde o projeto mais amplo de planejamento do texto a ser produzido (macroestrutura textual), passando por atividades de observação e análise de textos (leitura), a atividades de escrita e reescrita de trechos para trabalhar sua estrutura interna, envolvendo, por exemplo, diferentes mecanismos de coesão e coerência para a construção de textualidade do resumo e da resenha crítica.

As atividades envolviam discussão coletiva entre os discentes e o grupo sobre várias características linguístico-discursivas e sua relação com a situação de produção dos gêneros. Como as aulas eram realizadas nos laboratórios de informática, ao mesmo tempo em que participavam das discussões, faziam pesquisas na internet sobre o conteúdo das aulas. Além das discussões, os aprendizes se engajavam em atividades de produção de (re)escrita em duplas, que eram compartilhadas na plataforma de aprendizagem online.

Por fim, cada membro do grupo disponibilizava um horário semanal (1 hora) para atendimentos individuais aos discentes. Embora não fossem obrigados a marcar atendimento com os integrantes do grupo, os alunos eram encorajados a fazer isso, sobretudo se ainda tinham dúvidas pontuais após o fim das aulas práticas. Nesses atendimentos, então, que poderiam atender de uma a cinco pessoas no mesmo horário, os discentes traziam seus textos reescritos para análise e comentários dos integrantes do grupo.

Pode-se, assim, dizer, de forma mais ampla, que os três procedimentos adotados se constituem como um processo interligado de aprendizagem na perspectiva 
sociocultural vygotskyniana, pois os alunos se apropriam dos conhecimentos disponíveis do mundo (seus próprios, da sala de aula, da internet) a partir das relações com os outros (WELLS, 1999) para, então, desenvolverem seu conhecimento intrapessoal (VYGOTSKY, 2003). Por meio da interação entre discentes e o grupo (os pares mais experientes) e entre si mesmos, dentro de um contexto sociocultural específico, os discentes podem desenvolver progressivamente seus conhecimentos sobre os gêneros em questão.

De forma específica, foi possível notar que as aulas práticas, bem como os atendimentos individualizados, possibilitaram construir andaimes para os discentes por meio de quatro funções apontadas por Bruner, Ross e Wood (1976), que, por sua vez, dialogam com os conceitos de feedback e enriquecimento (BLOOM, 1971): 1) manutenção da direção: foi possível manter os alunos focados e motivados em relação ao objetivo proposto; 2) ênfase dos traços críticos: por meio de várias atividades de enriquecimento (BLOOM, 1971), envolvendo desde questões de ordem linguística às de ordem estrutural dos textos (macroestrutura), foi possível enfatizar determinadas características relevantes para a produção textual do resumo e da resenha. Essas características possibilitaram fornecer informações sobre a discrepância entre o que os aprendizes produziram e o que deveriam reconhecer para a produção dos seus textos; 3) controle da frustração: conseguiu-se reduzir o stress e a frustração dos aprendizes quando estes apresentavam dúvidas ou se mostravam ansiosos, desde as de caráter mais geral às mais específicas. Nesses casos, tanto nas aulas práticas quanto nos atendimentos individualizados, o grupo costumava interferir na realização das tarefas dos discentes, na tentativa de acalmá-los, trabalhando junto com eles. Em outras palavras, havia um feedback contínuo e individualizado (BLOOM, 1971), que respeitava os tempos e capacidades dos discentes, fazendo com que estes se sentissem motivados a continuar se desenvolvendo; e 4) demonstração: o grupo buscou criar modelos dos procedimentos mais apropriados para fazer com que os discentes fossem capazes de realizar as tarefas com mais eficiência, o que envolvia desde explicações de tarefas que ainda não haviam sido executadas pelo discentes àquelas já parcialmente realizadas, como as atividades de reescrita de trechos dos textos por eles escritos (períodos e parágrafos já elaborados).

Nota-se que o processo de produção dos alunos envolveu um conjunto de procedimentos que englobou atividades de observação e análise de textos, atividades de escrita e reescrita de trechos para trabalhar tanto a macroestrutura textual quanto sua estrutura interna, e reescrita de todo o texto inicial (resumo e resenha crítica), justamente para detectar as dificuldades discentes e assim ser possível ajustar os próprios objetivos da disciplina. Para complementar esse processo de ensino-aprendizagem, os discentes ainda fizeram uma autoavaliação, que envolveu questões reflexivas sobre a produção dos dois gêneros estudados. Abaixo, é reproduzido um quadro com as questões de autoavaliação dos alunos em relação à resenha crítica: 
Quadro 1 - Ficha de autoavaliação da resenha crítica

\begin{tabular}{|l|}
\hline \multicolumn{1}{|c|}{ FICHA DE AUTOAVALIAÇÃO DA RESENHA CRÍTICA } \\
\hline 1. Sua resenha tem a macroestrutura de uma resenha acadêmica? \\
\hline 2. Sua resenha está adequada ao(s) destinatário(s)? \\
\hline $\begin{array}{l}\text { 3. Você acha que compreendeu adequadamente o texto original e conseguiu se posicionar } \\
\text { de forma crítica em relação a ele? }\end{array}$ \\
\hline $\begin{array}{l}\text { 4. Você abordou em sua resenha as informações que o autor do texto original aponta como } \\
\text { as mais relevantes? }\end{array}$ \\
\hline 5. Além do conteúdo propriamente dito, você abordou: \\
\hline - dados sobre o autor do texto? \\
\hline - o conhecimento do autor em relação ao assunto? \\
\hline - a adequação da linguagem usada no texto para o público ao qual se dirige? \\
\hline • a organização global do texto? \\
\hline $\begin{array}{l}\text { 6. Você escolheu os organizadores textuais mais apropriados para ressaltar a relação entre } \\
\text { as ideias principais? }\end{array}$ \\
\hline $\begin{array}{l}\text { 7. Você escolheu os mecanismos linguísticos adequados para construir sua argumentação? } \\
\text { Você faria alguma alteração? Qual(is)? }\end{array}$ \\
\hline 8. Você procurou ser polido em suas críticas? Utilizou adjetivos? \\
\hline $\begin{array}{l}\text { 9. Você encontrou problemas de pontuação, de ortografia, de coerência, de coesão, frases } \\
\text { incompletas, erros gramaticais etc.? (circule-os) }\end{array}$ \\
\hline 10. Há outro aspecto que você avaliou e gostaria de comentar? Qual? \\
\hline
\end{tabular}

Fonte: Elaboração própria.

Por meio desses procedimentos, é possível afirmar que houve um considerável aprimoramento no processo de aprendizagem dos discentes. Isso porque, diferentemente de uma proposta de ensino conteudística, que culmina em uma avaliação do tipo somativa, de caráter retrospectivo e pontual, no fim de um determinado ciclo (bimestre, trimestre ou semestre), o que se procurou desenvolver na disciplina LA084, no período de 2013 a 2016, foi um tipo de avaliação processual (ao longo de todas as aulas), por meio de constantes feedbacks recursivos, na perspectiva de Cope e Kalantzis (2016), que se constituíram através de uma avaliação formativa, de caráter prospectivo e construtivo, fornecendo um contínuo feedback para os aprendizes e para o próprio grupo no decorrer das aulas da disciplina.

Por fim, realizou-se avaliação longitudinal, em que foram comparadas as produções iniciais dos discentes com suas produções finais. Nessa avaliação, foi possível, de fato, constatar o aprimoramento ocorrido durante todo o processo de aprendizagem, por 
meio dos avanços obtidos pelos discentes. O quadro a seguir compara, no período de 2013 a 2016, a média geral das quatro turmas (A, B, C e D) no resumo inicial (RI) e na resenha crítica inicial (RCI), com as notas finais do resumo (RF) e da resenha crítica (RCF):

Quadro 2 - Comparação da média geral das turmas A, B, C e D no resumo inicial (RI) e na resenha crítica inicial ( $\mathrm{RCI}$ ) com o resumo final (RF) e a resenha crítica final (RCF) no período de 2013 a 2016

\begin{tabular}{|c|c|c|c|c|c|c|c|c|c|c|c|c|c|c|c|}
\hline \multicolumn{3}{|c|}{2013} & \multicolumn{5}{c|}{2014} & \multicolumn{4}{c|}{2015} & \multicolumn{4}{c|}{2016} \\
\hline RI & RCI & RF & RCF & RI & RCI & RF & RCF & RI & RCI & RF & RCF & RI & RCI & RF & RCF \\
\hline 6.1 & 7.6 & 6.5 & 7.9 & 6.0 & 7.7 & 6.7 & 7.8 & 6.2 & 8.0 & 6.3 & 8.1 & 5.9 & 7.8 & 6.4 & 8.0 \\
\hline
\end{tabular}

Fonte: Elaboração própria.

\section{Considerações finais}

Buscou-se no presente artigo mostrar um movimento que parte da prática para a teoria; um movimento que deixa claro como as relações teoria-prática são constitutivas de um processo de investigação, e não categorias estanques. Isso porque a análise e discussão de cunho empírico dos procedimentos de ensino, utilizados em uma disciplina voltada exclusivamente para leitura e produção de textos acadêmicos, permitiu construir um novo objeto de pesquisa, uma vez que, inevitavelmente, levou a rever e inovar percursos teóricos trilhados, ao promover um diálogo entre o conceito de ZDP, da perspectiva sociocultural de Vygotsky, com conceitos de Mastery Learning (BLOOM, 1971), feedback recursivo (COPE; KALANTZIS, 2016) e Scaffolding (BRUNER; ROSS; WOOD, 1976).

Essa investigação de caráter qualitativo e empírico, que mobilizou o percurso teóricoanalítico aqui empreendido, teve como ponto central um conjunto de procedimentos de ensino-aprendizagem que leva em conta, antes de tudo, a construção coletiva de conhecimento, por meio da interação constante entre professor, bolsistas tutores, bolsistas apoiadores e alunos. Nessa perspectiva, desenvolveu-se um trabalho em que a avaliação assume também um caráter distinto do que tradicionalmente exerce: ao invés de uma avaliação de julgamento retrospectivo e pontual, no fim do de um determinado ciclo de ensino-aprendizagem, procurou-se desenvolver uma avaliação formativa, de caráter prospectivo e construtivo, fornecendo um contínuo feedback para os aprendizes e para o próprio grupo no decorrer das aulas da disciplina. Essa avaliação começou no início de cada edição da disciplina, em que se buscou entender e definir os procedimentos com os quais o grupo poderia trabalhar e intervir e os caminhos que os aprendizes ainda tinham que percorrer, o que permitiu planejar e desenvolver atividades 
que possibilitassem aos discentes um maior domínio dos dois gêneros trabalhos: o resumo e a resenha crítica.

Contudo, é preciso reconhecer que uma das dificuldades de aplicação da avaliação formativa é justamente sua operacionalização com grupos grandes de aprendizes, o que, obviamente, requer mais tempo do professor e mais tempo de aula. Em outras palavras, como apontava Bloom (1971), o tempo de aprendizagem e as condições de ensino precisam ser variáveis para que se possa determinar o sucesso dos alunos. De fato, se se pensar no contexto geral de ensino brasileiro, isso se configura como um obstáculo. Por outro lado, tal óbice não pode ser também encarado como um impedimento, mas como um desafio a ser enfrentado, se se objetiva pensar um processo de avaliação que vá além do famigerado modelo tradicional tripartite "IRA" (iniciação - resposta - avaliação).

O presente estudo, ao contrário, mostra que os procedimentos de ensinoaprendizagem adotados podem levar o aprendiz a novas formas de pensar, de categorizar, de analisar, enfim, de construir conhecimento. Por meio da mediação e dos andaimes necessários, construídos tanto com a ajuda de pessoas mais experientes, quanto por meio de seus próprios pares, o discente é, portanto, capaz de transformar a sua ZDP, isto é, o desenvolvimento potencial, aquele que se relaciona às capacidades e conquistas a serem por ele obtidas, em desenvolvimento real, concernente às conquistas atingidas.

Dentro dessa perspectiva, pode-se afirmar que as instituições de ensino possuem um papel fundamental, pois são responsáveis por essa intervenção pedagógica para desencadear o processo de ensino-aprendizagem por parte do docente, cuja função seria a de interferir na ZDP do aluno, na tentativa de promover avanços no seu desenvolvimento. Contudo, essa perspectiva somente se torna válida, segundo Vygotsky (2003), se a aprendizagem estiver à frente do desenvolvimento, em um processo social de construção de conhecimento. Daí cabe a todos nós nos perguntarmos se a escola e mesmo a universidade estão, de fato, promovendo um ensino que incentiva novas conquistas no desenvolvimento potencial do aprendiz, cujo foco se encaminha para o que Cope e Kalantzis (2016) chamam de "performance epistêmica complexa", ou se, ao contrário, continuam privilegiando e hierarquizando, a partir da perspectiva da meritocracia, um ensino centrado na cognição individual, no aprendizado individualista da escrita, contribuindo, assim, para a reprodução do status quo da cultura grafocêntrica que, como foi dito na introdução, impera desde o século XIX.

\section{Agradecimentos}

À Fundação de Amparo à Pesquisa do Estado de São Paulo (FAPESP) - Processo: 2016/19123-3. 
SILVA, P. Text production in higher education: rediscussing teaching-learning perspectives and procedures. Alfa, São Paulo, v.62, n.2, p.325-343, 2018.

- ABSTRACT: This study aims to present and discuss the results of an interpretive qualitative study of the teaching-learning procedures used in a discipline exclusively focused on reading and production of academic texts under the Programa de Formação Interdisciplinar Superior (Profis) of State University of Campinas (Unicamp), from 2013 to 2016. As its theoretical basis, this study uses Vygotsky's sociocultural perspective $(2000,2003)$ and, particularly, his concept of Zone of Proximal Development (ZPD), together with the concepts of Mastery Learning (BLOOM, 1971), recursive feedback (COPE; KALANTZIS, 2016) and Scaffolding (BRUNER; ROSS; WOOD, 1976). The results show that if text production is submitted to a formative evaluation process of prospective and constructive character, with continuous feedback to students, there may be new ways to build knowledge which, developed with the help of more experienced people or through their own peers, can transform their potential development level, the one related to the abilities and achievements to be obtained by the students, into an actual development level, which concerns the achievements they have already accomplished.

- KEYWORDS: Text production. Higher education. ZDP. Scaffolding. Mastery learning. Recursive feedback.

\section{REFERÊNCIAS}

BLANK, J. G. Vygostsky: o homem e sua causa. In: MOLL, L. C. Vygotsky e a educação: implicações pedagógicas da psicologia sócio-histórica. Porto Alegre: Artes Médicas, 1996. p. 31-56.

BLOOM, B. S. Mastery learning. In: BLOCK, J. H. (Ed.). Mastery learning: theory and practice. New York: Holt, Rinehart \& Wiston, 1971. p. 47-63.

BLOOM, B. S.; HASTING, J. T.; MADAUS, G. F. Handbook on formative and summative evaluation of student learning. New York: McGraw-Hill, 1971.

BRUNER, J. S.; ROSS, G.; WOOD, D. The role of tutoring in problem solving. Journal of Child Psychology and Child Psychiatry, [S.1.], v.17, p.89-100, 1976.

CERTEAU, M. A invenção do cotidiano 1: artes de fazer. 5. ed. Petrópolis: Vozes, 1984.

COPE, B.; KALANTZIS, M. (Ed.). E-learning ecologies. Nova Iorque: Routledge, 2016.

DOLZ, J.; NOVERRAZ, M.; SCHNEUWLY, B. Sequências didáticas para o oral e a escrita: apresentação de um procedimento. 2004. In: SCHNEUWLY, B.; DOLZ, J. Gêneros orais e escritos na escola. Tradução de Roxane Rojo e Glaís Sales Cordeiro. Campinas, SP: Mercado das Letras, 2004. p. 95-128. 
MOTTA-ROTH, D.; HENDGES, G. H. Produção textual na universidade. São Paulo: Parábola, 2010.

UNICAMP. Diretoria acadêmica. Disciplinas. [Campinas], 2014. Disponível em: $<$ http://www.dac.unicamp.br/sistemas/catalogos/grad/catalogo2015/coordenadorias/ 0025/0025.html\#LA084>. Acesso em: 27 jan. 2017.

VYGOTSKY, L. S. A formação social da mente. São Paulo: Martins Fontes, 2003.

VYGOTSKY, L. S. Pensamento e linguagem. São Paulo: Martins Fontes, 2000.

WELLS, G. Dialogic inquiry: towards a sociocultural practice and theory of education. New York: Cambridge University, 1999.

Recebido em 4 de outubro de 2017

Aprovado em 13 de fevereiro de 2018 
